\title{
Phonological Analysis of Errors in the Consonant Cluster System Encountered by Saudi EFL Learners
}

\author{
Eman M. Al-Yami \\ College of languages and Translation, Najran University, Saudi Arabia \\ Anwar A. H. Al-Athwary \\ Najran University, Saudi Arabia; \\ Sana'a University, Yemen
}

\begin{abstract}
This study investigates the pronunciation difficulty of selected English consonant clusters (CCs) encountered by Saudi EFL learners. The sample consisted of 134 female Saudi EFL students in their freshman year in the English Department at Najran University. Two instruments were used: a pronunciation test that assessed participants' $C$ C pronunciations in the onset and coda positions and a questionnaire that explored participants' attitudes towards their CC pronunciations. This study provides detailed data on the participants' pronunciation difficulties using Optimality Theory (OT). The results showed that the participants encountered CC pronunciation difficulties in both the onset and coda positions. However, most errors occurred in the coda position, especially for the four-consonant pattern (-CCCC). Participants used different strategies to simplify their CC pronunciations: epenthesis, deletion, substitution, or some combination thereof. Questionnaire data indicated that the participants attributed their pronunciation difficulties to inadequate knowledge of the pronunciation rules, insufficient language instruction, and native-language influence. The participants proffered some remedies to their difficulties, which included doing more pronunciation drills and offering a new course focused primarily on correct pronunciation. OT analysis revealed that onset clusters were mainly influenced by L1 ranking constraints whereas coda clusters were more influenced by universal Markedness constraints. OT indicated that the tendency to satisfy Markedness constraints over the Faithfulness constraints led the participants to use the above-mentioned simplification strategies.
\end{abstract}

Index Terms-Saudi EFL learners, consonant cluster, epenthesis, Optimality Theory, markedness and faithfulness constraints

\section{INTRODUCTION}

Proper English pronunciation is a fundamental component of effective communication, and thus it is perceived to be a cornerstone of intelligibility among speakers. However, second language (L2) learners of English are more likely to encounter obstacles, when it comes to communicating freely with English native speakers. In fact, this difficulty is somewhat anticipated, especially when the two languages being compared come from different backgrounds (Lado, 1957). English and Arabic, for instance, belong to dissimilar language families; the former is an Indo-European language while the latter is a Semitic language. Accordingly, they have different linguistic systems including phonology. Due to the dissimilarities between these two languages, L2 learners are more likely to develop and construct what might be called an 'interlanguage'. Linguistics factors would include the L1 influence on L2 (transfer) and the markedness (complexity) of the learned form, whereas non-linguistics factors, such as an L2 learner's attitude towards the target language, their age, the amount of exposure to the learned language they have had, the amount and quality of language instruction they have received, their lack of training, and so on, are also considered to be influential aspects (Barrios, 2018; Brown, 2000; Tarone, 1980). The current study is an endeavor to examine whether Saudi EFL learners face hurdles in pronouncing consonant clusters (CCs) with the aim of providing a thorough analysis of the interlanguage pronunciation of CCs. Moreover, it aims to identify the most common strategies and techniques used by Saudi EFL learners to simplify clusters under the framework of optimality theory (OT). Not only that, but also, it pays special attention to students' perception towards the pronunciation of CCs.

\section{A. English and Arabic Syllable Structure}

In the onset position, the English cluster system permits two consonant clusters (CC-) (e.g. /sp-/ as in 'spoon') and consonant clusters (CCC-) (e.g. /spl-/ as in 'spleen'). However, in the coda position, the coda cluster is asserted to be more complex than the onset one because it permits up to four consonants -that is, it may consist of -CC, -CCC, or CCCC patterns as /-sk/ in 'ask,'/-kts/ in 'acts', and /-ksts/ in 'texts', respectively (Yavaş, 2011). According to Roach (2000), clusters in the coda position are more varied and complicated than in the onset position because they may 
contain inflectional morphemes (e.g. /-s/) that are attached to nouns to form plurals, as in 'texts' /teksts/, or third person singular forms as in 'he takes' /hi: terks/. Moreover, /-ed/ is added to form the past tense of regular verbs and manifests itself as /-d/ when preceded by voiced sounds excluding/d/ or as /t/when preceded by voiceless sounds excluding /t/, as

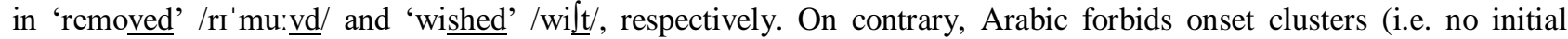
clusters are found in Arabic at all). Arabic doesn't permit CCs to exist in various positions as they do in English (AlMalki, 2014). Arabic permits clusters only in the coda position, as indicated by this simple structure: CV(CC). Some permissible -CC combinations are /-zb/, /-lb/, and /-bt/, as in /hizb/ 'party', /qalb/ 'heart', and /sabt/ 'Saturday', respectively (Na'ama, 2011).

\section{B. Optimality Theory $(O T)$}

OT is primarily a constraint-based approach built upon interacting constraints, and it claims that phonology reflects universally conflicting or competing constraints rather than rules. Though these constraints are assumed to be found throughout linguistics, they differ in term of ranking (ordering)-that is to say, ranking constraints can vary markedly from one language to another. As a result, learning another language might pose difficulty due to the violable constraints ranking. OT states that the surface pattern (optimal output) originates from conflicting constraints in a speaker's competence.

The Generator (GEN), Evaluator (EVL) and Constraints (CONs) are recognized as the vital components of OT. Accordingly, the relationship between input and output is utterly dependent upon these three constituents. GEN produces a large number of candidates, and EVL then evaluates and filters the candidates (CANDs) (i.e. outputs) iteratively until the optimal output is selected (also known as the "winner" or "harmonic candidate") (see Figure 1). Notwithstanding, this process is accomplished using two contrasted constraint families, namely, Faithfulness and Markedness.

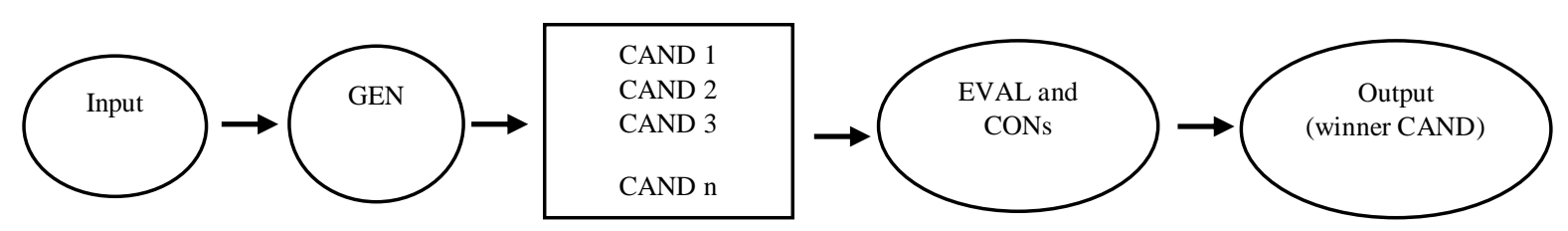

Figure 1. OT Paradigm

\section{Constraint Types}

The Faithfulness and Markedness constraint families are the core constraint families of OT. Kager (1999) described them as "two forces which are engaged in a fundamental conflict in every grammar" (p.4). The Markedness constraint family relies on evaluating the surface representation (output). More specifically, it governs the final shape of the output in the sense that it prevents the occurrence of certain configurations (i.e. marked or complex forms). There is an enormous number of Markedness sub-constraints, such as ONSET, NOCODA, and *COMPLEX (Kager, 1999). These particular sub-constraints are defined as follows:

ONSET: Onset within a syllable is compulsory.

NOCODA/*CODA: A syllable may not end in a coda (consonant).

*COMPLEX: No syllable is allowed to have CCs.

Unlike Markedness constraints, Faithfulness constraints evaluate the relationship between underlying representation (input) and surface forms (output). In short, they seek identical representation between input and output forms. McCarthy and Prince (1995) postulated three fundamental constraints to express Faithfulness, namely, MAX IO, DEP IO, and IDENT. These particular constraints require that each segment in the output appear exactly as it does in the input. Nevertheless, each one of them has a different segment prohibition.

MAX IO implies that deletion or reduction of a segment is prohibited.

DEP IO implies that insertion of a segment is prohibited.

IDENT implies that a feature change is prohibited, including voicing, place, and manner of articulation.

\section{Purpose of Study And Research Questions}

This study is significant in that it seeks to provide a deep insight into the interlanguage phonology pronunciation of English CCs in the onset and coda positions. It is considered a novelty in the sense that it goes a step further than previous studies by not only relying on percentages and means to explain such errors, but also by providing an OT analysis to gain a deeper understanding of this phenomenon. Moreover, it presents a unified treatment of the topic under study and offers some pedagogical suggestions that may assist Saudi EFL learners and English instructors at the College of Languages and other Saudi universities in understanding and correcting their students' phonological errors. In other words, this study is an attempt to provide potential solutions that may improve Saudi EFL learners' levels in pronunciation. This research is needed not only because it concentrates on linguistics factors (i.e., L1 influence and markedness), but also because it takes students' attitudes into account by explaining such phonological errors. Based on 
the findings of the current study, improper production of CCs is expected to be somewhat minimized because this study intends to widen teachers' horizons in the most common areas of difficulty in this regard. In addition, the outcomes of the present study might also help textbook designers incorporate CC problems encountered by Arab EFL learners - and Saudi EFL learners in particular - into materials to provide solutions.

This study seeks to answer the following questions: 1) Do Saudi female EFL learners encounter any difficulties in pronouncing consonant clusters in English? If so, which position (e.g. onset or coda) is the most challenging to pronounce?, 2)What kind of strategies and techniques do Saudi female EFL learners employ in pronouncing English consonant clusters?, and 3) What are students' attitudes toward the pronunciation of consonant clusters?

\section{LITERATURE REVIEW}

Complex English syllables that are comprised of CCs in the onset and coda positions have been explored in a great deal of literature. Different researchers from different backgrounds (e.g. China, Korean, Spain, Yemen, and Saudi Arabia) went to great lengths to identify factors that might induce the occurrence of the interlanguage phonology, the non-native version pronounced by L2 learners, particularly in the pronunciation of CCs. Hence, they started analyzing L2 learners' errors in articulating clusters as well as investigating the modification strategies used by L2 speakers. Most studies put the whole emphasis on the role of transfer as a way to account for all phonological errors made by L2 learners. For instance, Fatemi, Sobhani, and Abolhassani (2012) undertook a study to address the hindrances in pronouncing English CCs by Persian EFL learners. The Persian language has a few simple structures, such as CV and VCC. Consequently, when the participants pronounced CCs that did not exist in their native language, they tended to insert a vowel as a repair tool to facilitate their pronunciation. For instance, 'proved'/pru:vd/ was pronounced incorrectly by some of the participants as /porovd/, /peruved/, and /pirovd/.

The same concern was also revealed by Jabeen, Mahmood, and Asghar (2012), but in reference to Punjabi, the spoken language in Pakistan. As ascertained by these writers, Punjabi speakers of English adopted phonological processes such as vowel insertion to meet the clash between the constraints of native language and target language. It appeared that vowel addition could take place either at the beginning of clusters (e.g. /sp-/ was mispronounced as / $\underline{\text { osp}}$-/as in 'spin'), or between clusters (e.g. /str-/ was mispronounced as /sgtr-/ as in 'straw'). These findings were also reported in other studies (e.g. Bouchhioua, 2019; Hago and Khan, 2015; Keshavarz, 2017). On the other hand, other studies stressed the role of markedness. Chen (2011), for instance, investigated the pronunciation of the CC- and CCC-patterns by nine Taiwanese students. He asserted that the Chinese phonological system did not allow for the CC pattern at all; thus, the participants were expected to face difficulty in uttering both types (i.e. CC- and CCC-). Surprisingly, participants made many more errors in pronouncing marked clusters like CCC-compared to less-marked ones like CC-, although these two structures were not found in their native language. Elsaghayer (2014) also examined the erroneous pronunciation of CCs spoken by 20 Libyan students at the Misurata University Language Center. He deduced that clusters posed obstacles for participants, especially the most complex patterns, which were the -CCC coda clusters. Clusters were split by inserting / / / or /I/, for instance. Additionally, /-dz/ and /-mps/ were incorrectly pronounced as /diz/ and /-mbəz/, respectively. Rungruang (2017) pointed out that shorter clusters were less marked than longer ones. As a result, clusters with longer lengths, such as -CCCC, were more likely to pose a difficulty (i.e. the hardest one to be acquired) compared to shorter ones, like -CC, that were presumed to be easily acquired by L2 learners.

Na'ama (2011) and Nogoud (2020) also highlighted the impact of various extra-linguistic factors that induced pronunciation errors, such as unsuitable teaching aids, incompetent or unqualified teachers, and participants' lack of awareness of their own errors. Indeed, methods, materials, and activities designed for teaching English pronunciation might also constitute a serious impediment when it comes to improving pronunciations.

There is a great consensus among scholars on the most common simplification strategies adopted by L2 learners in articulating CCs; these are vowel epenthesis, substitution, and deletion (Chan 2007; Jayaraman 2010). Hansen (2001) revealed that numerous numbers of Korean EFL learners tended to use epenthetic technique after the final consonant as in "held"/held/, they tend to add the short vowel/ə/ to create a new syllable; thus it is pronounced as /heldə/. Similar findings were also reported by other studies (e.g. Kharma and Hajaj, 1989). In the same line, Al-Sammer (2014) and Jayaraman (2010) claimed that when a syllable ended with inflectional morphemes, such as a plural, participants tended to omit the last cluster to simplify their articulation. In addition, they asserted that the deletion tendency was also applied to certain final cluster combinations (e.g. -mp, -pt, -kt, -nt, -bt).

On the contrary, Al-Aqlobi (2013) noticed that Saudi EFL learners faced problems in uttering CCs and epenthesis was the dominant strategy. For instance, the onset clusters in the word 'sport'/sps:t/ was mispronounced as /isps:t/, inserting the short vowel /i/. Moreover, Alenazi (2016) argued that Saudi EFL learners tend to substitution strategy when a certain phoneme within cluster is not allowed in Arabic. For example, the cluster/pr-/ was mispronounced as /br-/ as in 'pride' because the stop voiceless sound / $\mathrm{p} /$ is not found in Arabic.

Some other studies use OT analysis to explain CC mispronunciations. Hideki (2004) examined the simplification strategies used by Japanese EFL learners in articulating complex onset and coda clusters within the framework of OT. He succinctly expounded the impact of universal markedness on the interlanguage pronunciation of CCs. He noted that unmarked patterns emerged in Japanese EFL learners' pronunciations of CCs due to conflicting constraints. As asserted 
by the author, participants resorted to inserting a vowel to break or alter complex clusters to satisfy the two dominant CONs-*COMPLEX and MAX-IO -at the cost of violating the lower ranked DEP-IO.

Turkustani (2011) also used OT to explain the interlanguage pronunciations of coda CCs pronounced by 30 Arabic speakers enrolled at the English Language Institute (ELS) in Malaysia. The findings showed that Arabic EFL learners resorted to ranking the Markedness constraint higher than the Faithfulness constraints in order to avoid complex coda clusters. The ranking was shown as follows: *COMPLEX CODA, *CCC >> MAX-IO, DEP-IO, IDENT-IO.

As opposed to the previous studies that were restricted to analyzing a particular combination of the onset or coda positions, this study provides a more comprehensive investigation of both types of cluster structures (i.e. onset and coda). Moreover, it examines participants' own self-assessments of their pronunciations of English CCs. To this end, it adopts two instruments to gather accurate data: a pronunciation test and a questionnaire. As far as Saudi EFL/ESL literature is concerned, exploring the pronunciation of CCs from the standpoint of OT is quite rare. Hence, we think that using OT analysis might be deemed an appropriate approach in elucidating errors committed by Saudi EFL learners in pronouncing CCs in both positions. Although prior investigations have employed diverse theories (e.g. sonority scale distance, $\mathrm{CA}, \mathrm{MDH}$ ) to analyze errors, OT is widely accepted as one of the most effective frameworks to investigate problems within syllable structures (McCarthy, 2008).

\section{METHOD}

\section{A. Research Design}

The study adopted a quantitative descriptive design that employed statistics and percentages for data interpretation. Besides the statistical analysis, the researchers strived to yield deeper insight into this phenomenon, and so for this reason, OT analysis of CCs was also demonstrated. This constraint-based analysis assisted in accounting for observed error patterns as accurately as possible. In other words, this analysis examined and exposed the simplification techniques used by Saudi EFL participants in pronouncing CCs in the onset and coda positions. Furthermore, it explored whether or not errors pronounced by Saudi EFL learners were triggered solely by transferring the ranking constraints from L1 to L2.

\section{B. Participants}

The subjects of the study were 134 female Saudi EFL students specializing in the English Department at the College of Languages and Translation, Najran University, KSA. Only 30 of these 134 participants were willing to participate in the pronunciation test due to a self-ascribed lack of confidence. However, all 134 participants volunteered to participate in the questionnaire portion of the study. The participants were in their freshmen year and were considered to be at the beginner level of English based on an English placement test given by the English Department.

\section{Instruments}

The key instruments used to gather data were a pronunciation test and a questionnaire that included both closedended and open-ended questions. The pronunciation test was constructed to assess participants' oral performance in the pronunciation of CCs. The list consisted of 40 target clusters, half of which covered clusters in the onset position and half of which covered clusters in the coda position. The tested words were adopted from previous studies (e.g. Jayaraman, 2010; Turkustani, 2011). The participants were instructed to read aloud 40 target CCs in the word list as clearly as possible and at a normal reading speed.

On the other hand, questionnaire examined the participants' own perceptions toward their pronunciations of CCs. It was divided into two main sections. The first section collected the participant's demographic information (e.g. age, number of years spent learning English, etc.), and the second section collected data about the participant's attitudes towards pronouncing CCs. This second section was further divided into four subsections as follows: part A: The participants' overall opinion concerning their CC pronunciations, part B: The participant's feelings towards common causes that might lead to mispronouncing CCs, part C: The participant's perspective regarding some suggested solutions, and part D (Open-ended questions): The participant's opinion about their own pronunciations of English CCs.

Parts A, B, and C were measured on a five-point Likert scale (strongly agree, agree, uncertain, disagree, and strongly agree) and consisted of a list of 15 items preceded by clear instructions and definitions of the terms used.

Part D was comprised of two open-ended questions intended to give participants a chance and space to ponder and list any factors that might also exacerbate their mispronunciations of CCs and to offer suggestions for techniques that might also improve their pronunciations in a classroom setting.

\section{Procedure}

Since this study was conducted during the COVID-19 pandemic, meeting with the participants in person, face-to-face, was problematic. Consequently, online data collection was performed remotely from the safety and comfort of the participants' own homes. They were invited to meet the researcher on Zoom, an online conferencing platform, which supports virtual meetings over the Internet. The researcher then set up and scheduled meeting dates amenable to the individual participants. Meeting links were then sent to each participant, after which the researcher met and conversed with each participant in one-on-one sessions. Once a participant was present at a meeting, the researcher began the 
session with some a brief icebreaking, welcome speech designed to put the participant at ease and alleviate any anxiety or speech hesitation that they might be experiencing due to undergoing an unfamiliar process with a stranger.

Then a list of 40 words was displayed on the screen, and each participant was given some time to peruse the word list. Once the participant was ready to begin, she was reminded that only her voice would be recorded. Participants were instructed to read the words in the word loudly and clearly and to pause for two seconds between words to facilitate data extraction later. Each session took only a few minutes of each participant's time. The researcher met with five participants each day until all participants had been interviewed. The whole interview and data-collection process took about one week. Concerning the second instrument, the questionnaire, the researcher posted an online questionnaire for the participants to access individually via links sent to them via email. They were requested to click on the emailed link to access the questionnaire, to read each statement carefully, and to respond by clicking on the appropriate Likert scale item for each statement. Then they were requested to answer two open-ended questions to solicit any amplifying information and suggestions they might want to offer on the topic of this study. The completed responses were then stored and kept for later data analysis.

\section{ANALYSIS AND RESUlts}

The collected data were analyzed, using Microsoft Office Excel 2010 and SPSS statistical software version 21. Descriptive and inferential statistical analyses were performed to answer the research questions.

A. Do Saudi Female EFL Learners Encounter Any Difficulties in Pronouncing Consonant Clusters in English? If So, Which Position - Onset or Coda - Is the Most Challenging to Say?

To discover the most challenging consonant cluster positions to pronounce, an ANOVA Analysis and Descriptive Statistics were performed.

TABLE 1

ANOVA ANALYSIS OF USE OF CONSONANT CLUSTERS IN ONSET AND CODA POSITIONS

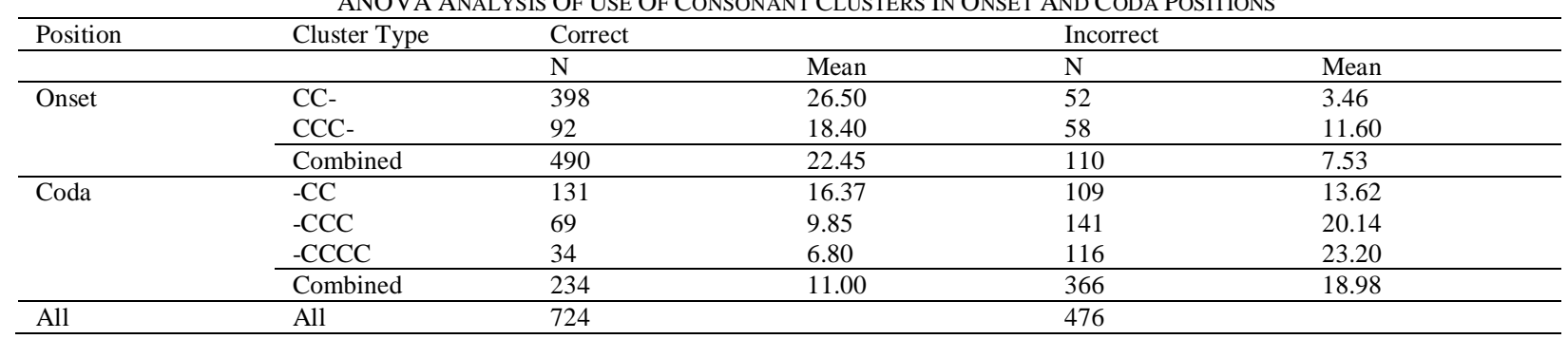

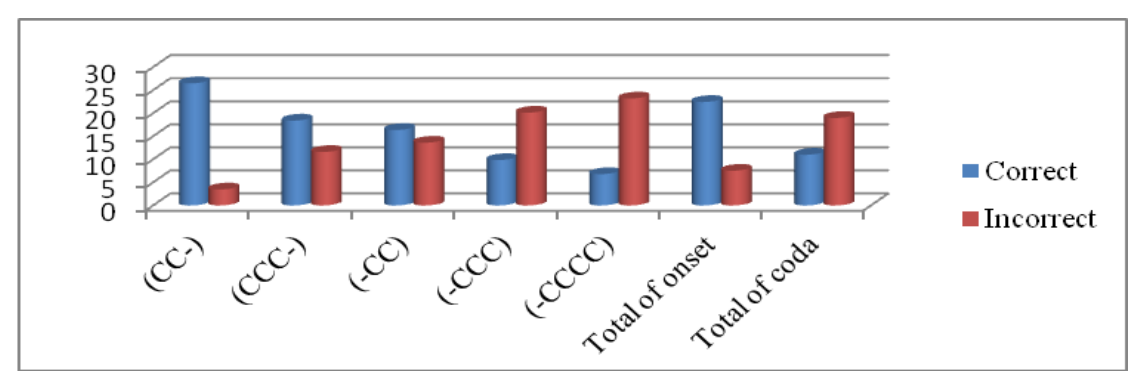

Figure 2. Results of Consonant Cluster Pronunciations in Onset and Coda Positions

As illustrated in Table 1 and Figure 2 the means value of using the CCs correctly was high at the onset position $(\mathrm{M}=22.45)$; the mean for $\mathrm{CC}$ - was 26.50 while the $\mathrm{CCC}$ - was 18.40 . However, the mean was low at the incorrect responses $(\mathrm{M}=7.53)$; then the means for $\mathrm{CC}$ - and CCC- were 3.46 and 11.60, respectively. For coda CCs, the correct responses had a low combined mean $(\mathrm{M}=11.00)$; the means for $-\mathrm{CC}$, and $-\mathrm{CCC}$, and $-\mathrm{CCCC}$ were 16.37, 9.85, and 6.80, respectively. The incorrect responses had a high combined mean $(\mathrm{M}=18.98)$; the means for $-\mathrm{CC},-\mathrm{CCC}$, and $-\mathrm{CCCC}$ were 13.62 , 20.14, and 23.20, respectively. The conclusion was that participants faced more difficulty pronouncing coda CCs than onset CCs.

\section{B. What Kind of Strategies and Techniques Do Saudi Female EFL Learners Employ to Pronounce English Consonant Clusters?}

To answer this question, the percentages of the modification techniques were calculated for each CC type in both onset and coda positions. The results are summarized and graphically depicted in Table 2 and Table 3 and in Figure 3 and Figure 4. 
TABLE 2

SimplafiCATION Strategies Of THE PRONUNCIATION OF ONSET CONSONANT Cluster

\begin{tabular}{|c|c|c|c|c|c|}
\hline \multirow{2}{*}{ Onset Cluster Type } & \multirow{2}{*}{$\%$ Errors } & \multicolumn{4}{|c|}{ Simplification Strategies (\%) } \\
\hline & & Epenthesis & Deletion & Substitution & Various \\
\hline CC- & 11.0 & 5.0 & 2.0 & 4.0 & 0 \\
\hline CCC- & 38.5 & 22.6 & 10.6 & 1.3 & 4 \\
\hline
\end{tabular}

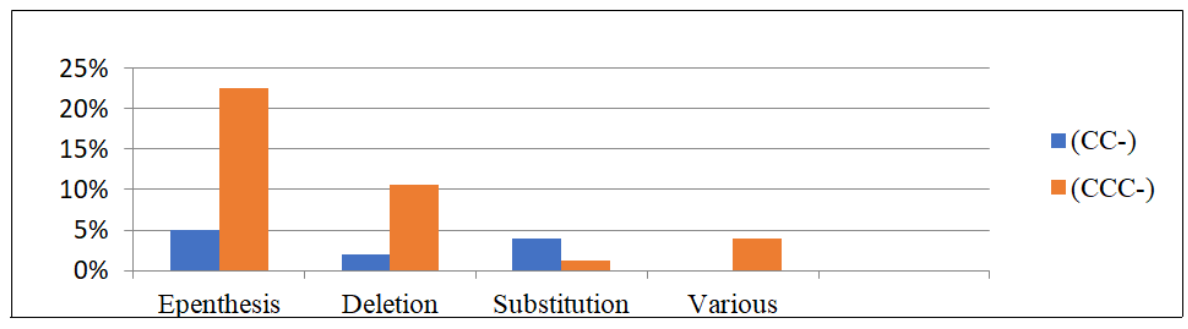

Figure 3. Simplification Strategies of the Pronunciation of Onset Consonant Cluster

As depicted in Table 2 and Figure 3, the participants applied different strategies and techniques to pronounce onset CCs. Those adopted patterns were categorized into four categories: epenthesis, deletion, substitution, and a combination of these strategies, collectively categorized as "various". Overall, the epenthesis strategy was the most dominant simplification strategy preferred by the participants comparing to other strategies (e.g. deletion and substitution). In Figure 3, the CC- cluster pronunciations consisted of 5\% epenthesis errors, $2 \%$ deletion errors, and $4 \%$ substitution errors, giving a total of $11 \%$. However, there was no evidence of using more than one strategy for the CC- cluster pronunciations, so the "Various" percentage is zero.

For CCC- cluster errors, the errors consisted of $22.60 \%$ epenthesis errors, $10.60 \%$ deletion errors, $1.30 \%$ substitution errors, and $4.00 \%$ various errors, giving a total of $38.50 \%$. The various errors were situations where some participants applied two different strategies to pronounce the CCC- cluster, such as insertion and deletion.

TABLE 3

SimPlifiCATION STRATEGIES OF THE PRONUNCIATION OF CODA CONSONANT CLUSTERS

\begin{tabular}{llllll}
\hline \multirow{2}{*}{ Coda Cluster Type } & \multirow{2}{*}{$\%$ Errors } & \multicolumn{2}{l}{ Simplification Strategies (\%) } & \\
\cline { 3 - 6 } & & Epenthesis & Deletion & Substitution & Various \\
-CC & 45 & 32.5 & 4.6 & 6.6 & 1.25 \\
-CCC & 67 & 33.8 & 6.0 & 10.0 & 17.00 \\
-CCCC & 77 & 33.0 & 35.0 & 0 & 9.00 \\
\hline
\end{tabular}

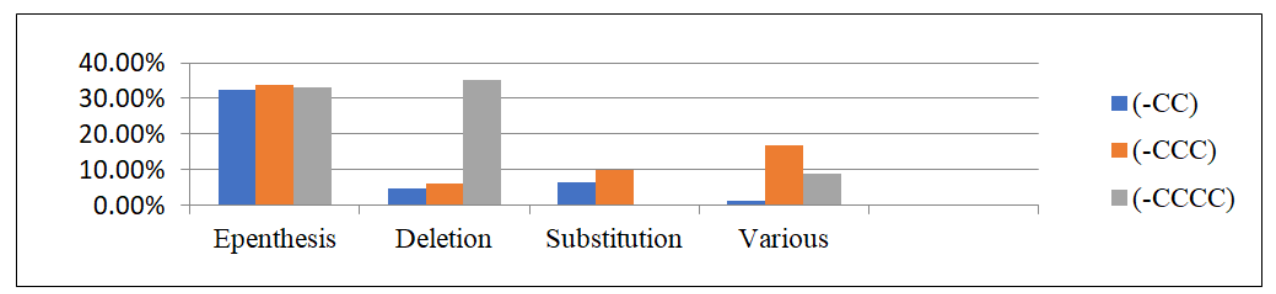

Figure 4. Simplification Strategies of the Pronunciation of Coda Consonant Clusters

As illustrated in Table 3 and Figure 4, the participants applied the same strategies to pronounce coda clusters as well. The epenthesis error rates were the highest compared to other strategies (e.g. deletion and substitution). For the -CC structure, the $45 \%$ errors consisted of $32.5 \%$ epenthesis errors, $4.6 \%$ deletion errors, and $6.6 \%$ substitution errors, and $1.25 \%$ various errors, which manifested as combining two different strategies. For the -CCC structure, the $67 \%$ errors consisted of $33.8 \%$ epenthesis errors, $6.00 \%$ deletion errors, $10.00 \%$ substitution errors, and $17.00 \%$ various errors. For the -CCCC structure, the $77 \%$ errors consisted of $33.0 \%$ epenthesis errors, $35.00 \%$ deletion errors, $0 \%$ substitution errors, and $9.00 \%$ various errors. There was no evidence of using a substitution strategy for this structure. The "various" errors were cases where participants use two different strategies, such as substitution and insertion.

C. What Are Students' Attitudes towards the Pronunciation of Consonant Clusters?

This question is divided into four parts:

\section{Students' Overall Opinions in the Pronunciation of Consonant Clusters (CCs)}

To identify the students' general attitudes towards pronouncing English consonants clusters, descriptive statistics were used to elicit the means and standard deviation of their responses on the questionnaire items. 
TABLE 4

DescriPtive Statistics Of Students AtTitudes Towards The PRonunciation Of English CCS

\begin{tabular}{llllll}
\hline No. & Item & M & SD & Skewness & Kurtosis \\
\hline 1 & $\begin{array}{l}\text { I believe the proper pronunciation of CCs is a one of the key aspects } \\
\text { of the effective communication. }\end{array}$ & 4.14 & .79 & -.71 & .133 \\
2 & $\begin{array}{l}\text { I find it difficult to pronounce CCs correctly. } \\
\text { I feel that pronouncing a set of consonants in a sequence is more }\end{array}$ & 3.21 & 1.05 & -.05 & -.951 \\
3 & $\begin{array}{l}\text { difficult than pronouncing a single consonant. } \\
\text { I feel that pronouncing the four members of cluster in English is the }\end{array}$ & 3.59 & .92 & -.29 & -.233 \\
& most complex and hardest task such as 'texts'. & 3.52 & 1.07 & -.31 & -.654 \\
\hline & Total means & 3.60 & .58 & -.21 & .279 \\
\hline
\end{tabular}

Table 4 reveals that the overall mean of all the items is 3.60, indicating that the students' collective opinions towards learning English CCs pronunciation was high.

\section{Student Attitudes towards Some Factors Contributing to the Mispronunciation of CCs}

Descriptive statistics were utilized to explore students' perception toward some factors that may impede their pronunciation in terms of consonant clusters.

TABLE 5

DESCRIPTIVE STATISTICS OF STUDENT ATTITUDES TOWARD CERTAIN FACTORS CONTRIBUTING TO CC MiSPRONUNCIATIONS

\begin{tabular}{|c|c|c|c|c|c|}
\hline No. & Item & $\mathrm{M}$ & SD & Skewness & Kurtosis \\
\hline 5 & $\begin{array}{l}\text { I believe that the major source of difficulty in English CCs is } \\
\text { due to the difference that exists between English and Arabic. }\end{array}$ & 3.36 & 1.06 & -.631 & -.016 \\
\hline 6 & $\begin{array}{l}\text { The bi-cluster (-cc) in the final-word (e.g. 'tent') causes no } \\
\text { trouble for me to pronounce it because it exists in Arabic } \\
\text { (e.g. bint 'a girl'). }\end{array}$ & 3.791 & .90 & -.385 & -.279 \\
\hline 7 & $\begin{array}{l}\text { I think the lack of knowledge of some of pronunciation rules } \\
\text { may contribute to the difficulty of CCs production (e.g. [x] } \\
\text { is pronounced as two consonants: /ks/ as in the word 'box' or } \\
\text { /gz/ as in 'exam'. }\end{array}$ & 3.72 & 1.11 & -.78 & -.06 \\
\hline 8 & $\begin{array}{l}\text { I receive little language instruction in terms of } \mathrm{CCs} \\
\text { pronunciation. }\end{array}$ & 3.66 & 1.26 & -.31 & -.48 \\
\hline 9 & $\begin{array}{l}\text { I think that the problem in uttering CCs correctly is due to } \\
\text { the lack of pronunciation training. }\end{array}$ & 3.84 & .88 & -.304 & -.23 \\
\hline 10 & $\begin{array}{l}\text { I am not sure how to pronounce the CCs, containing the } \\
\text { inflectional suffixes, like -ed in the past tense (i.e., whether } \\
\text { to pronounce /d/ or /t/ as in 'watched', 'cleaned, 'asked'. }\end{array}$ & 4.13 & .94 & -.98 & -.44 \\
\hline
\end{tabular}

As shown in Table 5, the total means of students' responses towards certain factors that contributing to the difficulties in pronouncing English CCs was 4.20, indicating that their perceptions were high. The highest response of the participants was for Item 10, showing that the participants agreed that the most vital factor was the lack of knowledge of how to pronounce the CCs, containing the inflectional suffixes like/-ed/ in the past tense (i.e., whether to pronounce $/ \mathrm{d} /$ or $/ \mathrm{t} /$ as in 'watched', 'cleaned', 'asked'. Their perception values $(\mathrm{M}=4.13, \mathrm{SD}=.94)$ indicated exceedingly high perception. However, the lowest response for the participants was Item 5 $(\mathrm{M}=3.36, \mathrm{SD}=1.06)$, indicating that their views toward language transfer as a major factor was moderate.

\section{Perception toward Some Suggested Solutions}

To understand students' perceptions about toward some suggested solutions, descriptive statistics were used to elicit the means and standard deviation of their responses on the questionnaire items.

TABLE 6

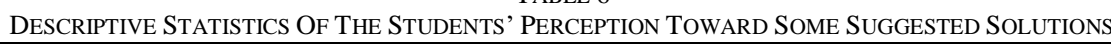

\begin{tabular}{|c|c|c|c|c|c|}
\hline No. & Item & $\mathrm{M}$ & SD & Skewness & Kurtosis \\
\hline 11 & $\begin{array}{l}\text { I consider pronunciation drill to be very beneficial technique in } \\
\text { teaching CCs. }\end{array}$ & 4.22 & .922 & -1.045 & .465 \\
\hline 12 & $\begin{array}{l}\text { I think improving pronunciation of CCs requires constant listening to } \\
\text { English native speakers. }\end{array}$ & 3.76 & 1.105 & -1.017 & .049 \\
\hline 13 & $\begin{array}{l}\text { I believe that sufficient practice of pronouncing CCs would help } \\
\text { master them. }\end{array}$ & 4.04 & 1.044 & -1.189 & .864 \\
\hline 14 & $\begin{array}{l}\text { I think teachers should draw my attention to the correct } \\
\text { pronunciation of clusters, especially those patterns that are not found } \\
\text { in Arabic, like three and four clusters. }\end{array}$ & 3.40 & 1.007 & -1.111 & .54 \\
\hline 15 & $\begin{array}{l}\text { I feel that teachers should raise my awareness of various } \\
\text { pronunciation of CCs, especially those that contain the inflectional } \\
\text { markers such the plural form /-es, s/ (when to pronounce it } / \mathrm{s} / \text { or } / \mathrm{z} / \text {, } \\
\text { as in 'cleans', 'mates'. }\end{array}$ & 4.06 & 1.046 & -.961 & .067 \\
\hline & Total Means & 3.90 & .80 & -.851 & -.252 \\
\hline
\end{tabular}


As shown in Table 6 and the total means came out to be 3.90, indicating that the students' overall attitudes towards some suggested solution to improve $C C$ pronunciation was high. Item 11 gained the highest score $(M=4.22, S D=.922)$, indicating that the pronunciation drill was a greatly beneficial technique in teaching CCs. However, Item 15 garnered lower scores $(\mathrm{M}=4.06, \mathrm{SD}=1.046)$, indicating that focusing on the correct pronunciation of clusters, especially not found in Arabic, like three- and four-consonant clusters, was moderate.

\section{Open-Ended Questions.}

Students may feel limited in expressing their feelings when responding to a structured questionnaire, so the researcher also utilized two open-ended questions at the end of the questionnaire to give the participants an opportunity to freely report their opinions about contributing factors that they felt might also impede their proper pronunciation of CCs. In addition, it gave them the liberty to provide some suggested solutions to improve their pronunciations.

Q1. From your point of view, what are the factors that could also contribute to the mispronunciation of consonant clusters, other than those mentioned?

In general, students stressed some other factors which they believed might also adversely affect their pronunciations of CCs. Among these factors were lack of self-study and practice, and distracting environments, not to mention the complexity of the CCs structures itself. Moreover, insufficient and delayed feedback in class could also lead to less than optimum pronunciations of CCs. Lastly, students argued that being taught by non-native English speakers could also result in improper pronunciation of CCs.

Q2. Do you have any further suggestions for improving the pronunciation of consonant clusters?

The majority of the participants suggested adding extra classes to improve their listening and pronunciation skills. Additionally, students hoped to take specialized subjects such as phonetics and phonology starting from the first level. Another proposed solution was to use dictionaries to help improve pronunciations, for example, the Oxford and Cambridge dictionaries. They further believed that teachers should integrate pronunciation practice with other English lessons. The participants also emphasized the importance of getting constant feedback for their pronunciations. Finally, they wished to be taught by native English speakers.

\section{OT Analysis of the Interlanguage Pronunciation of Consonant Clusters in Onset and Coda Positions}

The following analysis shows the interlanguage pronunciations of each type of CC (CC-, CCC-, -CC, -CCC, -CCCC). The data obtained suggested a set of ranked constraints that reflect an obvious violation of the Faithfulness constraints, namely DEP-IO, MAX-IO and IDENT-IO. The violation of these constraints occurred in order to satisfy the Markedness constraints, resulting in simplifying CCs. To illustrate this, CCs were modified in terms of vowel epenthesis, which indicated a serious violation of the DEP-IO constraint. The CCs could also be repaired by a deletion strategy, which implied a serious violation of the MAX-IO constraint. Last but not least, CCs could be modified by a segmental substitution, which resulted in a violation of the IDENT-IO constraint. In a nutshell, all three cases indicated that the Markedness constraint*COMPLEX ranked above the DEP-IO, MAX-IO and IDENT-IO, that is, Faithfulness constraints. The Arabic and English languages have differing constraint hierarchies, as follows:

Arabic: ONSET CONDITION $>$ > COMPLEX ONSET $>>$ MAX-IO $>>$ DEP-IO $>>$ IDENT English: MAX-IO, DEP-IO >>ONSET CONDITION, COMPLEX ONSET $>>$ IDENT

\section{Onset Position}

TABLE 7

1 CC\# CLUSTER PRONOUNCED By SAUdi EFL LEARNERS

\begin{tabular}{|c|c|c|c|c|c|c|}
\hline a. & $\mathrm{C}_{1} \mathrm{C}_{2} \mathrm{V \#}$ & $\begin{array}{l}\text { ONSET } \\
\text { Condition }\end{array}$ & $\begin{array}{l}\text { Complex } \\
\text { ONSET } \\
* !\end{array}$ & MAX-IO & DEP-IO & IDENT \\
\hline c. & $\ldots \mathrm{C}_{2}<>\mathrm{V \#}$ & & & $*$ & $*$ & \\
\hline d. & $\mathrm{C}_{1}<>\mathrm{C}_{2} \mathrm{~V} \#$ & & & & $*$ & \\
\hline e. & $\mathrm{C}_{1} \mathrm{C}_{\mathrm{x}} \mathrm{V \#}$ & & $* !$ & & & $*$ \\
\hline
\end{tabular}

The symbols used were adopted from Jabbari and Arghvan (2010) where \# represents a syllable boundary, <> indicates an inserted vowel, ... represents a deleted consonant, and $\mathrm{C}_{\mathrm{X}}$ indicates a substituted consonant. As shown in Table 7, candidate d, $\mathrm{C}_{1}<>\mathrm{C}_{2} \mathrm{~V}$, was the optimal candidate for Saudi EFL learners as it only violated one constraint, DEP-IO. Based on the analyzed data, epenthesis was more frequent among other strategies in the onset position. It came out to about $5 \%$ out of $11 \%$ errors.

However, it is worth mentioning that a few students tended to substitute one sound with another without changing the structure of CCs (4\%). Thus, the constraint hierarchy of the substitution strategy was ONSET $>>$ MAX-IO >>IDENT-IO. 
TABLE 8

CCC\# PRONOUNCED BY SAUDI EFL LEARNERS

\begin{tabular}{|c|c|c|c|c|c|c|}
\hline \multicolumn{2}{|c|}{ Candidate } & \multirow[t]{2}{*}{$\begin{array}{l}\text { ONSET } \\
\text { Condition }\end{array}$} & \multirow{2}{*}{$\begin{array}{l}\text { Complex } \\
\text { ONSET } \\
* * !\end{array}$} & \multirow[t]{2}{*}{ MAX-IO } & \multirow[t]{2}{*}{ DEP-IO } & \multirow[t]{2}{*}{ IDENT } \\
\hline a. & $\mathrm{C}_{1} \mathrm{C}_{2} \mathrm{C}_{3} \mathrm{V \#}$ & & & & & \\
\hline b. & $\mathrm{C}_{1} \mathrm{C}_{2} \ldots \mathrm{V} \#$ & & $* !$ & $*$ & & \\
\hline c. & $\ldots \mathrm{C}_{2} \mathrm{C}_{3} \mathrm{~V} \#$ & & $* !$ & $*$ & & \\
\hline d. & $\Leftrightarrow<C_{1} C_{2} \cdot C_{3} V \#$ & & & & $*$ & \\
\hline e. & $\mathrm{C}_{1}<>\mathrm{C}_{2} \cdot \mathrm{C}_{3} \#$ & & & & $*$ & \\
\hline f. & $\mathrm{C}_{1} \mathrm{C}_{\mathrm{x}} \mathrm{C}_{3} \mathrm{~V} \#$ & & $* * !$ & & & $*$ \\
\hline
\end{tabular}

As illustrated in Table $8,\left\langle>\mathrm{C}_{1} \mathrm{C}_{2} \cdot \mathrm{C}_{3} \mathrm{~V}\right.$ and $\mathrm{C}_{1}<>\mathrm{C}_{2} \cdot \mathrm{C}_{3} \mathrm{~V}$ were optimal candidates due to their violating on the lowerranked constraints. Candidates $\mathrm{a}, \mathrm{b}, \mathrm{c}$, and $\mathrm{f}$ were ruled out because they violated the highest-ranked constraint COMPLEXONSET. Hence, it can be said that epenthesis in the CCC- structure was the most preferable strategy. Based on the data analysis, it came out to about $22.6 \%$ out of $38.6 \%$ errors.

\section{Coda Position}

In addition to the MAX-IO, DEP-IO and IDENT, other constraints should be introduced to account for coda clusters for each type of coda clusters, namely COMPLEXCODA (two clusters are not allowed) and CODA (more than two clusters are not tolerated). Moreover, other constraints, such as $* \mathrm{CCC}$ (three clusters is prohibited), *CCCC (four clusters is not acceptable), should also be utilized to account for -CCC and-CCCC clusters as much as possible. Arabic and English have the following hierarchical constraints:

Arabic: CODA CONDITION >> MAX-IO, DEP-IO >>COMPLEX CODA >IDENT

English: MAX-IO >>DEP-IO $>>$ CODA CONDITION $>>$ COMPLEX CODA $>>$ IDENT

Here, CODA CONDITION constraints in Arabic imply no more than two consonants are acceptable whereas in English no more than four consonants are acceptable.

TABLE 9

\#CC CLUSTER PRONOUNCED BY SAUDI EFL LEARNERS

\begin{tabular}{|c|c|c|c|c|c|}
\hline \multicolumn{2}{|c|}{ Candidate } & Complex CODA & MAX-IO & DEP-IO & IDENT \\
\hline a. & $\# \mathrm{VC}_{1} \mathrm{C}_{2}$ & $* !$ & & & \\
\hline b. & $\# \mathrm{~V} \ldots \mathrm{C}_{2}$ & & $* !$ & & \\
\hline c. & $\# \mathrm{VC}_{1}<>\mathrm{C}_{2}$ & & & $*$ & \\
\hline d. & $\# \mathrm{VC}_{1} \mathrm{C}_{\mathrm{X}}$ & $* !$ & & & * \\
\hline e. & $\# \mathrm{VC}_{\mathrm{x}} \mathrm{C}_{2}$ & $* !$ & & & $*$ \\
\hline
\end{tabular}

As depicted in Table 9, candidates, d, and e were not optimal candidates because they violated the highly ranked Markedness constraint *COMPLEXCODA. Likewise, candidate $\mathrm{b}$ was ruled out because it was in violation of the Faithfulness constraint MAX-IO. As a result, candidate $\mathrm{c}$ won out as the optimal output since it satisfied the Markedness constraint *COMPLEXCODA while violating only the lower-ranked Faithfulness constraint DEP-IO. Based on the data analysis, it came out to be $32.5 \%$ out of $45 \%$ errors.

TABLE 10

\#CCC CLUSTER PRONOUNCED BY SAUdi EFL LEARNERS

\begin{tabular}{|c|c|c|c|c|c|c|}
\hline \multicolumn{2}{|c|}{ Candidate } & $* \mathrm{CCC}$ & MAX-IO & Complex CODA & DEP-IO & IDENT \\
\hline a. & $\# \mathrm{VC}_{1} \mathrm{C}_{2} \mathrm{C}_{3}$ & $* !$ & & & & \\
\hline b. & $\# \mathrm{~V} \ldots \mathrm{C}_{2} \mathrm{C}_{3}$ & & $* !$ & $*$ & & \\
\hline c. & $\# \mathrm{~V} \ldots \mathrm{C}_{2}<>\mathrm{C}_{3}$ & & $* !$ & & $*$ & \\
\hline d. & $\approx \mathrm{VC}_{1} \cdot \mathrm{C}_{2}<>\mathrm{C}_{3}$ & & & & $*$ & \\
\hline e. & $\# \mathrm{VC}_{\mathrm{x}} \mathrm{C}_{2} \mathrm{C}_{3}$ & $* !$ & & & & $*$ \\
\hline
\end{tabular}

As illustrated in Table 10, candidates a, b, and e were excluded from being optimal candidates because they were in conflict with the highest-rank constraint*CCC. Similarly, candidate c was also ruled out because it violated Faithfulness constraint MAX-IO by deleting a consonant segment. Thus, candidate $\mathrm{d}$ was chosen as the winner output because it had the least severe violations. It can be inferred that it satisfies the *COMPLEXCODA constraint at the cost of violating the lower-ranked constraint DEP-IO. Based on the data analysis, it came to about $33.8 \%$ out of $67 \%$ errors.

TABLE 11

\#CCCC CLUSTER PRONOUNCED By SAUDI EFL LEARNERS

\begin{tabular}{|c|c|c|c|c|c|}
\hline \multicolumn{2}{|c|}{ Candidate } & $* \mathrm{CCCC}$ & MAX-IO & DEP-IO & IDENT \\
\hline a. & $\# \mathrm{VC}_{1} \mathrm{C}_{2} \mathrm{C}_{3} \mathrm{C}_{4}$ & $* !$ & & & \\
\hline b. & $\approx \# \mathrm{VC}_{1} \mathrm{C}_{2} \mathrm{C}_{3} \ldots$ & & $*$ & & \\
\hline c. & $\# \mathrm{VC}_{1} \ldots \mathrm{C}_{\mathrm{x}} \mathrm{C}_{4}$ & & $*$ & & $*$ \\
\hline d. & $\# \mathrm{VC}_{\mathrm{x}} \mathrm{C}_{2} \mathrm{C}_{3} \mathrm{C} 4$ & $* !$ & & & $*$ \\
\hline e. & $\# V C_{1} C_{2}<>C_{3}<>C_{4}$ & & & $* *$ & \\
\hline f. & $\# \mathrm{VC}_{1} \mathrm{C}_{2}<>\mathrm{C}_{3} \mathrm{C}_{4}$ & & & $*$ & \\
\hline
\end{tabular}


As shown in Table 11, candidate $\mathrm{b}$ and $\mathrm{f}$ were selected as optimal candidates. Most students preferred the deletion strategy (35\%) when pronouncing complex clusters -CCCC. The vowel insertion strategy occurred 33\% of the time, not quite as common as the deletion strategy. Obviously, candidates a, c, and e were disqualified from being winner outputs due to having multiple violations.

\section{DISCUSSION}

The present study is conducted to investigate the pronunciation of English onset and coda clusters by Saudi EFL learners. Quantitative descriptive and OT analyses were performed. This section discusses, compares and contrasts the result of the study with relevant literature in the same area. Based on data analysis Saudi female EFL learners had trouble pronouncing English CCs in the onset (CC-, CCC-) and coda (-CC, -CCC, -CCCC) positions. This conclusion agrees with other Arab studies (Elsaghayer, 2014; Na'ama, 2011). However, the difficulty hierarchy varies, that is to say, Saudi EFL learners encountered more problems in pronouncing CCs in the coda position more than in the onset position. Not only that, but another interesting result was also uncovered; the difficulties were not equal, even within the same position. The CC-structure was the least difficult type $(\mathrm{M}=3.46, \mathrm{SD}=3.9)$ (e.g. / pr-/ mispronounced as /br-/ in 'private') compared to the CCC- structure, $(\mathrm{M}=11.6, \mathrm{SD}=3.04)(\mathrm{e} . \mathrm{g}$. /skw-/ was reduced to /sk-/ in 'square') in the onset position. The same also held true for coda clusters. It appeared that the most difficult pattern was the -CCCC structure (M=23.2, $\mathrm{SD}=2.04$ ) (e.g. /-ks $\theta \mathrm{s} /$ was mispronounced as /-ks $\theta /$ and /-ksis/ in 'sixths'). The difficulty hierarchy can be summarized as follows: CC- $<$ CCC- $<-\mathrm{CC}<-\mathrm{CCC}<-\mathrm{CCCC}$

Students used different strategies to pronounce CCs. For example, epenthesis strategy which was the most preferable simplification strategy in pronouncing CC-, CCC-, -CC and -CCC. For instance, the clusters /gl-/ as in 'glamorous', /str-/ as in 'street', /-bd/ as in 'robbed, /-sks/ as in 'masks' were mispronounced as /gəl-/, /sitr-/, /-bid/ and /kist/, respectively. Nevertheless, this result is in contrast with Al-Sammer (2014), and Jayaraman (2010), all of whom argued that the commonly used repair strategy to produce the -CCC structure was segmental deletion rather than an epenthesis strategy. However, deletion was the most dominant strategy in pronouncing-CCCC, for example, the cluster /-mpts/ in 'attempts' was mispronounced as /-mpits/. Other strategies such substitution (e.g. /pr/ was mispronounced as /br/ in 'private') and some combination thereof, like insertion and deletion (e.g./spl-/ mispronounced as /isp-/ as in 'split') were also used but they were less common.

Factors that could account for student errors in CCs pronunciation can be classified into two types: linguistics factor such L1 influence and Markedness, and the second type is non-linguistics such as an L2 learner's attitude towards the target language, their age, the amount of exposure to the learned language they have had, the amount and quality of language instruction they have received, their lack of training. Since students experience problems in pronouncing the more marked structure - CCCC than the less marked structure - CC, this evidence is in support with Markendess factor. This outcome is also in line with other studies (e.g. Chen, 2011; Hansen, 2001; Turkestani, 2011). Nevertheless, those studies only concentrated on particular structures in onset or coda positions.

Another factor that could also account for student errors is the L1 influence; student faced more difficulties in those structures that are not found in Arabic, so they tended to resort to Arabic syllabification structure. This is also supported by previous studies (e.g. Fatemi et al., 2012; Hago and Khan, 2015; Keshavarz, 2017). Indeed, the questionnaire indicated to some other contributing factors such as lack of knowledge of the correct way to pronounce CCs containing inflectional suffixes such as /-ed/, /-s, and /-es/. Moreover, lack of self-study and practice and being in a distracting environment and also lack of language instruction. This seems to resonate with Na'ama (2011), as he pointed out that lack of knowledge was deemed an influential factor behind the difficulties in the pronunciation of CCs. However, it is still in contrast with some researchers (e.g. Keshavarz, 2017; Jabeen et al., 2012) who attributed students' errors only to the dissimilarities between L1 and L2.

Regarding OT analysis, it provided an explanation of simplifying CCs. Overall, the interlanguage pronunciation of CCs emerged as a result of an interaction demonstrated between the Markedness and Faithfulness universal constraints. There was an obvious tendency towards unmarked patterns, implying that the Markedness constraints (e.g. COMPLEX) were ranked higher than the Faithfulness constraints (e.g. MAX and DEP). Due to this conflict, repair strategies such as epenthesis, deletion and substitution were used.

In the case of onset, OT revealed that the mispronunciation of the $\mathrm{CC}$ - and $\mathrm{CCC}$ - structures were mostly affected by L1 ranking transfer. As mentioned earlier, the Arabic rank hierarchy is as follows: ONSET CONDITION $>>$ COMPLEX ONSET $>>$ MAX-IO $>>$ DEP-IO $>>$ IDENT.

Based on the data analysis, participants resolved the conflict between L1 and L2 by directly transferring their native language ranking constraints. For example, the CC- structure was broken up by adding an intrusive vowel, pronounced as CVC-. The explanation behind this phenomenon is that participants tended to follow the same pattern as their native language, that is, by satisfying the COMPLEX constraint at the expense of violating the MAX-IO and DEP-IO constraints. Consequently, epenthesis and deletion strategies were used to pronounce such clusters. In short, the ranking hierarchy of the interlanguage onset pronunciation is as follows: Markedness CON (COMPLEXONSET) >> Faithfulness CON (MAX-IO, DEP-IO)

This result is also in congruence with previous studies (e.g. Hideki, 2004; Turkestan, 2011), but these studies were limited to examining only coda clusters. 
With respect to the coda clusters, there was to some extent an overlap between the effect of L1 influence and universal markedness factors. Regarding L1 influence, some patterns like-CCC and -CCCC, are not found in Arabic, so participants might transfer their native language structure. As previously stated, Arabic has the following ranking: CONDITIONCODA $>>$ MAX-IO, DEP-IO $>>$ COMPLEXCODA $>$ IDENT

\section{CONCLUSION}

Investigating the pronunciation problems of CCs by Saudi EFL learners has been heretofore underexplored by preliminary literature in terms of examining errors within an OT framework, considering both linguistic and extralinguistic factors, and exploring student's perceptions in this regard. Therefore, the significance of this study evolved from those shortcomings. The current study focused on the pronunciation difficulties of CCs in the onset and coda positions encountered by Saudi female EFL learners in the English department at Najran University. It provided empirical evidence that Saudi female EFL learners face pronunciation difficulties in CC pronunciations in both the onset and coda positions. It should be noted that most of errors occurred in the coda positions containing inflectional suffixes. The results also revealed that almost all Saudi female EFL learners continue to modify CCs in their normal English speech. The analysis of the present study demonstrated that the dominant and preferred mispronunciation strategies used was epenthesis, even though deletion was commonly used in -CCCC pronunciations.

In the case of onset clusters, OT uncovered that modifications and adjustments were due to the impact of L1 influence ranking. Concerning coda cluster modifications, OT argues that simpler structures are less marked than more complex structures; consequently, was less marked than CCC-, and -CC was in turn less marked than -CCC, gradually leading to the most marked structure -CCCC. Therefore, it can be inferred that -CCCC was the most challenging structure as a result of the universal markedness effect. Saudi female EFL learners' perceptions toward the importance of pronouncing CCs properly were positive. Besides the impact of transfer and markedness, some other extra-linguistic factors also lie behind the pronunciation problems faced by Saudi female EFL learners, such as lack of adequate pronunciation instruction, pronunciation knowledge, and exposure to an English-language-immersion environment. Consequently, students look forward to minimizing the impact of those factors and to enhancing their pronunciations. In a nutshell, this study emphasizes that L1 interference is not the sole source behind pronunciation problems, as some prior literature affirmed. Thus, universal markedness, along with other extra-linguistic factors, should be taken into account, given the essential roles they play in pronunciation learning and teaching.

\section{REFERENCES}

[1] Al-Aqlobi, O. (2013). Difficulties in pronouncing and perceiving English word-final consonant clusters among Saudi ESL learners. Unpublished Master's Thesis, Southern Illinois University.

[2] Alenazi, A. R. (2016). The production of English coda clusters by Aljouf Arabic speakers. International Journal of English Linguistics, 6 (2), 34-42. doi:10.5539/ijel.v6n2p34

[3] Al-Malki, H. (2014). Acoustic investigation of production of clusters by Saudi second language learners of English. Unpublished Master's Thesis, Florida International University.

[4] Al-Sammer, M. (2014). Patterns of coda clustering simplification in RP English by Omani female students: A generative perspective. Journal of the College of Arts, (69), 25-56.

[5] Barrios, S.L. (2018). Interlanguage Phonology. The TESOL Encyclopedia of English Language Teaching, 1-7. https://doi.org/10.1002/9781118784235.eelt0230

[6] Bouchhioua, N. (2019). Epenthesis in the production of English consonant clusters by Tunisian EFL learners. Applied Linguistics Research Journal, 3(4), 33-44.

[7] Brown, H. (2000). Principles of Language Learning and Teaching (4 $4^{\text {th }}$ ed).NY: Pearson Longman.

[8] Chen, S. (2003). Acquisition of English onset clusters by Chinese learners in Taiwan. Paper presented at the Linguistics and English Language Postgraduate Conference. University of Edinburgh. http://www.lel.ed.ac.uk/ pgc/archive/2003/proc03/Szuwei_Chen03.pdf ( accessed 23/ 12/2020)

[9] Elsaghayer, M. A. (2014). Markedness approach to the production of English consonant clusters among the Libyan Arabic speakers of English. Faculty of Arts Journal, (2), 8-24.

[10] Fatemi, M., Sobhani, A., \& Abolhassani, H. (2012). Difficulties of Persian learners of English in pronouncing some English consonant clusters. World Journal of English Language, 2(4), 69-75.

[11] Hago, O. E., \& Khan, W. A. (2015). The pronunciation problems faced by Saudi EFL learners at secondary schools. Education and Linguistics Research, 1(2), 85-99.

[12] Hansen, J. (2001). Linguistic constraints on the acquisition of English syllable codas by native speakers of Mandarin Chinese. Applied Linguistics, 22(3), 338-365. https://doi.org/10.1093/applin/22.3.338

[13] Hideki, A. (2004). Pronunciation difficulties in EFL and optimal L2 syllable. Research Reports of Tsuruoka National Collage of Technology, 39, 61-66.

[14] Jabbari, A. A. \& Arghavan, L. (2010). Optimality theoretic account of acquisition of consonant clusters of English syllables by Persian EFL learners. Journal of English Language Teaching and Learning, 2(17), 69-109.

[15] Jabeen, F. Mahmood, M, \& Asghar, M. (2012). Vowel Epenthesis in Pakistani English. Interdisciplinary. Journal of Contemporary Research in Business, 3(10), 224- 233.

[16] Jayaraman, S. (2010). Acquisition of pronunciation of consonant clusters by Arabic speakers of English as a second language. Sino-US English Teaching, 7(1), 46-54.

[17] Kager, R. (1999). Optimality Theory. Cambridge: Cambridge University Press. 
[18] Keshavarz, M. H. (2017). Syllabification of final consonant clusters: A salient pronunciation problem of Kurdish EFL learners. Iranian Journal of Language Teaching Research, 5(2), 1-14.

[19] Kharma, N., \& Hajjaj, A. (1989). Errors in English among Arabic Speakers: Analysis and Remedy. Longman Group UK Limited.

[20] Lado, R. (1957). Linguistics Across Cultures: Applied Linguistics for Language Teachers. Michigan: University of Michigan Press.

[21] McCarthy, J. (2008). Doing Optimality Theory: Applying Theory to Data. Oxford: Blackwell.

[22] McCarthy, J. \& Prince, A. (1995). Faithfulness and reduplicative identity. In J. Beckman, L. W. Dickey, \& S. Urbanczyk (Eds.), University of Massachusetts occasional papers in linguistic (pp. 249- 384). Amherst, MA: GLSA Publications.

[23] Na'ama, A. (2011). An Analysis of errors made by Yemeni university students in the English consonant-clusters system. Damascus University Journal, 27 (3), 145-161.

[24] Nogoud, J. A. (2020). Phonotactic Cruciality of English Initial and Final Consonant Clusters' Pronunciation on Sudanese EFL Undergraduates. European academic research, 8(3), 2131-1251.

[25] Roach, P. (2000). English phonetics and phonology: a practical course ( ${ }^{\text {rd }}$ ed.). Cambridge: Cambridge University Press.

[26] Rungruang, A. (2017). Consonant cluster acquisition by L2 Thai speakers. Canadian Center of Science and Education, 10 (7), $216-231$.

[27] Tarone, E. (1980). Some influences on the syllable structure of interlanguage phonology. International Review of Applied Linguistics (IRAL), 18 (2), 139-152.

[28] Turkustani, A. (2011). Analyzing Arabic-English interlanguage coda consonant clusters: Optimality theoretic approach. Unpublished Master Thesis, University Malaya, Malaysia.

[29] Yavaş, M. (2011). Applied English Phonology (2 $2^{\text {nd }}$ ed.). United Kingdom: Wiley-Blackwell.

Eman M. Al-Yami is an M.A. scholar at Department of English, College of Languages and Translation, Najran University, KSA. She got her B.A. in English from Najran University, KSA. Her main interests of research are applied linguistics, phonetics and phonology, and CALL.

Anwar A. H. Al-Athwary is currently an associate professor at Najran University, KSA. He received his M.A. in Linguistics from Jawaharlal Nehru University, India, and his Ph.D. in linguistics from Aligarh Muslim University, India. His special areas of interest are lexical borrowing, phonetics and phonology, and linguistic landscape. 